\title{
Gerações, modernidade e subjetividade coletiva
}

\author{
JOSÉ MAURÍCIO DOMINGUES
}

RESUMO: As gerações como problema sociológico, conceitual e empiricamente, têm recebido certa atenção recentemente. Todavia permanecem subteorizadas, de modo geral e em termos de suas configurações particulares na modernidade. Este artigo revê a literatura sociológica e antropológica sobre o tema e propõe-se a reconceituá-lo fazendo uso do conceito de "subjetividade coletiva", para então retomar a sua análise nos quadros da sociedade moderna.

er um membro da espécie humana significa ser também parte de uma de suas subcoletividades. De forma variável e mutável historicamente, várias delas têm cumprido essa função. Por outro lado, tanto como seres biologicamente enraizados quanto como social e historicamente condicionados, passamos por várias fases no curso de nossas vidas, fases essas que compartilhamos de modo mais ou menos completo com outros indivíduos. Nascemos, amadurecemos biológica e socialmente, envelhecemos e morremos. Ao longo desse complexo processo, composto por várias e distintas fases, ocupamos posições sociais particulares, desempenhamos tarefas específicas e contemplamos o surgimento e o desabrochar, o ocaso e o desaparecimento de coletividades que nos precederam e que nos sucederão, contribuindo positiva ou negativamente, para isso. Alegrias e sofri-

PALAVRAS-CHAVE: modernidade, subjetividade, gerações.

Professor do IUPERJ/ UCAM 
mentos se abrigam nessas diversas etapas e nas passagens de uma a outra, colorindo-as com seus tons peculiares. Quer os percebamos ou não, aceitemolos ou os recusemos, essas transições se inserem em processos mais amplos de mudança social, da qual são parte e para a qual contribuem. A despeito de sua variabilidade histórica, trata-se efetivamente de processos que possuem um caráter universal. Todas as formações sociais os incluem e todas têm de lidar com eles e seus efeitos mais abrangentes.

A questão das gerações vem se colocando com grande força nas pesquisas e nos debates das ciências sociais. Sem dúvida o tema da juventude tem destaque nesse campo, porém a "Terceira Idade" acabou por assumir igualmente relevância para essa discussão, com pouco interesse tendo sido por ora despertado por outras etapas do ciclo da via. Mas do ponto de vista teórico, conceitual amplo, a questão ainda parece demandar cuidados e atenção sistemática, conquanto após um período de hibernação razoavelmente longo esforços recentes terem sido feitos nessa direção. Este artigo buscará, primeiramente, discutir criticamente algumas contribuições nessa área. A partir disso avançaremos no sentido de pensar as gerações em conjunção com o conceito de subjetividade coletiva, do qual se porá como uma instância; isso nos permitirá, creio, repensar e desenvolver o tema em tela com mais acuidade e precisão. Enfim, buscar-se-á uma teorização sobre as gerações especificamente na modernidade.

É interessante observar de início que o tema da subjetividade recebeu uma forte torção nas últimas décadas, deixando de lado seu caráter centrado, isto é, transparente e organizado, bem como abandonando seu isolamento e autodeterminação. Em lugar disso afirmou-se uma visão muito mais contingente, que destaca sua opacidade possível e freqüente para o próprio sujeito, bem como o fato de ser ela hoje percebida como tecida no meio de processos interativos (cf. Domingues, 1995, especialmente cap. 7). Curiosamente, entretanto, as teorias recentes das gerações na sociologia parecem desconhecer esse movimento. Por outro lado, contribuições empíricas amiúde apresentam a mesma tendência a perceber as gerações como coletividades homogêneas, embora isso contraste com vários outros estudos que evidenciam, como veremos, a intensa pluralização dos estilos de vida e identidades na modernidade avançada. Ora, é precisamente uma tese homogeneizadora e que tendencialmente aponta para as gerações como coletividades centradas, com identidade clara e mesmo organização, que se buscará evitar aqui: trata-se de propor um conceito de gerações que escape desses equívocos, permitindo assim uma visão que contemple a heterogeneidade, o descentramento e a interatividade das gerações sociais, sem deixar de lado seu substrato material, inclusive biológico. O conceito de subjetividade coletiva será fundamental nesse sentido (cf. Domingues, 1995, 1996 e 1999a).

Segundo essa perspectiva teórica, a vida social é tecida e se constitui como uma rede interativa, multidimensional, na qual atores individuais e coletividades se influenciam de forma mútua causalmente. Assim as dimen- 
sões hermenêutica e material, as dimensões das relações de poder e do espaço-tempo social que conformam as subjetividades coletivas são estabelecidas sob a influência de outras coletividades. No caso em tela não é possível compreender, por exemplo, como a juventude se vê e vê a sociedade sem entender como os "idosos" a vêem, e a sociedade, e vice versa. Ou seja, as dimensões hermenêuticas (normativas, cognitivas e expressivas) das diversas coletividades geracionais se influenciam umas às outras; não se trata, portanto, muito ao contrário, de analisar suas dimensões hermenêuticas, nem quaisquer outras, isoladamente e sem referência a outras coletividades. É mister que esse jogo mútuo de influências seja assinalado e assimilado para que possamos de fato perceber como as coletividades particulares e a vida social em geral se constituem. Isso não implica intencionalidade e organização das diversas coletividades, conquanto este possa ser o caso: com "níveis variáveis de centramento", as subjetividades coletivas têm impacto umas sobre as outras tendo isto como objetivo ou não, com freqüência portanto como uma conseqüência não intencional da ação, por vezes internamente contraditória e heterogênea em termos de intencionalidade, de seus membros.

É importante frisar que isso permite conceituar as diversas gerações, mas também relacioná-las com outras subjetividades coletivas, com as quais se entrecruzam, como gêneros, raças, empresas, as diversas divisões do estado moderno, a família, etc., elas mesmas também constituídas, em sua multidimensionalidade, relacionalmente. Evidentemente, as gerações têm-se subdividido em classes, gêneros e raças desde sempre. Contudo, a pluralização dos estilos de vida, a multiplicação de "tribos" e grupos com sobretudo distintas sensibilidades e preferências estéticas, mas por vezes igualmente com comportamentos diferenciados, agudiza a heterogeneidade dessas subjetividades coletivas. Se levamos em conta uma tendência assinalada pela literatura sociológica internacional no sentido de uma crescente individualização da vida social, com chances de vida diferenciadas e cada vez mais contingentes, inclusive dentro das mesmas coletividades de classe e profissionais, essa complexificação social se exponencializa. Em que medida uma geração pode pôr-se em movimento de forma centrada - isso é, contando com forte identidade e organização, e a partir daí com intencionalidade comum - é uma questão que deve ser vista sempre como contigente. A pluralização das subjetividades coletivas na modernidade tornou isso ainda mais agudo.

\section{Gerações, coortes e ciclos de vida}

O conceito de gerações de Mannheim é ainda a mais interessante e completa tentativa sociológica de dar conta do tema, embora as contribuições posteriores na antropologia sejam particularmente significativas. Todos os autores que recentemente retomaram o tema lançam mão amplamente da teorização de Mannheim. Segundo ele, cuja obra sofreu em grande medida a influência de Hegel, as gerações se punham antes de mais nada como um tipo 
Nesse sentido, tratase de tese bastante diferente da de Eisenstadt (1956), cuja brilhante contribuição funcionalista, que detalharei adiante, centra-se na reprodução antes que na mudança social. de coletividade muito proximamente articulada aos processos históricos de mudança social - nesse sentido se colocavam como um princípio de explicação até certo ponto alternativo às classes tal qual se apresentam no "materialismo histórico". ${ }^{1}$ Sucedendo-se no tempo, as gerações se apresentavam como a "não simultaneidade do simultâneo" (expressão que Mannheim toma emprestada de Pinder), o que significa que cada "ponto do tempo" é um "espaço de tempo" que se organiza "polifonicamente” (Mannheim, 1928, pp. 517-8).

Se as gerações se apresentam como uma alternativa à teoria das classes em Marx, compartilham com elas caraterísticas que seriam fundamentais para a construção de Mannheim, que outrossim para isso se apóia de fato, implicitamente, antes em uma conceituação weberiana do que em uma abordagem efetivamente marxista. Gerações se definem primeiramente por compartilharem uma posição biológica - nascimento e morte, sem que possam ser todavia reduzidas a isso. Sua articulação social é obviamente decisiva. Em primeiro lugar se põem como "locais geracionais" (Generationslagerung), inertes e estruturais, possibilitando que se compartilhem posições sociais - de modo semelhante às classes no que tange à estrutura econômica e de poder. Assim as gerações são ainda mera "potencialidade", possibilidade apenas, sem que a elas corresponda uma consciência, tal qual as classes, que não se tornam necessariamente "para si". Embora isso não seja em momento algum explicitado, parece evidente que ademais as gerações se definem em seu isolamento e autodeterminação, sem que se ponha em questão as relações entre elas. Sobre isso se assentam as gerações como conjuntos de "relação" (Generationszusammenhang) amplos e algo vagos, que implicam outrossim experiências, "vivências" comuns, que fazem com que a geração enquanto "potencialidade" avance na direção da conformação de "grupos concretos" (Konkretegruppen) variados. Aquelas relações amplas e indistintas de qualquer forma se estabelecem a partir do momento em que experiências comuns e laços emergem, quando "destinos comuns" (gemeisamen Schicksalen) se delineiam, em que "intenções básicas" e "princípios de construção" se tecem, ao passo que certos grupos que biologicamente poderiam conformar uma geração não ultrapassam o estágio de meros agregados de nascimento. Por outro lado, aqueles grupos concretos fundam "unidades de geração" (Generationseiheiten), que podem ser múltiplas, e se enraízam em contatos pessoais, espirituais e emocionais, embora possam ulteriormente tornar-se independentes disso. Aquelas unidades, contudo, compartilham conteúdos mais concretos e específicos, bem como laços mais estreitos, "concretos", e podem estar em contradição e luta umas com as outras (cf. Mannheim, 1928, pp. 524-7 e 542-7).

O legado de Mannheim continua a ser até certo ponto subvalorizado na sociologia, mas sua abordagem do "problema das gerações" vem atraindo a atenção recentemente. Isso é o que se pode verificar na contribuição recente de Turner e Eyerman, que, recorrendo ao conceito de "habitus" de Bourdieu, o qual fundem com a contribuição pioneira de Mannheim, pro- 
põem um conceito de "memória coletiva" e de geração que reproduz exatamente a perspectiva de que esse tipo de coletividade seria homogêneo e centrado, assim como tendendo a defini-lo a partir de suas próprias experiências como coletividades, portanto em independência do que se passa com outras gerações. Essa tentativa me parece deficiente em vários aspectos, sobretudo por utilizar-se do excessivamente duro conceito de "habitus" de Bourdieu, e por radicalizar uma limitação já presente ao menos em parte nos escritos de Mannheim no que se refere à teorização das "subjetividades coletivas", que eles observam com a suposição de um alto nível de centramento como elemento básico de sua definição daquele tipo de coletividade, questão que logo enfrentarei abaixo com mais detalhes. A eles interessa definir gerações a partir não só de experiências compartilhadas mas também de se organizarem em movimentos coletivos com clara identidade e demarcação, embora sublinhem (ainda apoiando-se em Bourdieu) que as gerações se constituem em meio a lutas por recursos escassos, seja no plano material seja no cultural (cf. Turner e Eyerman, 1998, especialmente pp. 93-5).

Corsten avançou algumas idéias interessantes, conquanto o tema da subjetividade coletiva seja trabalhado de forma igualmente problemática. Para ele as gerações existem como "identidades coletivas", para cuja construção experiências comuns são de fato fundamentais. Para isso, entretanto, é necessário estabelecer conceitualmente uma "mediação" entre a "localização social" e a "experiência social" - o que se obtém através do uso coletivo de signos e da linguagem. Isto se concretiza por meio de "discursos" específicos, com o que as gerações podem "identificar e se localizar no processo histórico" através de sua "autotematização". "Semânticas históricas" permeiam esses discursos e criam fronteiras entre as gerações, gerando "círculos culturais" de "grupos específicos de idade" que compartilham a "interpretação e a articulação de tópicos" (Corsten, 1999, pp. 261-2). Assim Corsten busca dar um sentido contemporâneo, no que é clara a influência da chamada "virada linguiística", às discussões de Mannheim sobre as gerações, suas "relações" amplas e sua experiência comum. Além disso ele assinala que as gerações somente se constroem em processos de interação com outras gerações, ao delas se "distinguirem": o discurso de "gerações que co-existem" é "co-construtivo". Isso se apresenta como um elemento fundamental dos processos construtivos externos que se somam aos processos internos, ambos sendo fundamentais para a compreensão de como a experiência de uma geração é tecida como tal (cf. Corsten, 1999, pp. 265-7). Logo, ele distancia-se de Mannheim ao postular que os processos interativos são fundamentais para a constituição das gerações.

O problema é que Corsten vê nessa demarcação e homogeneidade das gerações um princípio fundamental para sua definição. Por isso chega mesmo a dizer que certos grupos de idade caem em desvãos históricos, nunca conformando uma geração em sua juventude, quando compartilhariam experiências comuns: falta-lhes originalidade, uma semântica histórica co- 
Estudos empíricos sobre gerações, a exemplo de pesquisa quantitativa ampla realizada sobre a juventude carioca (cf. Mynayo et alii., 1999), com frequiência incorrem em equívoco semelhante. mum, que lhes permitisse interpretar-se como um grupo homogêneo e delimitado (cf. Corsten, 1999, p. 266). ${ }^{2}$ Se se tem em mente que interpretar deve ser considerado uma forma de ação individual e de movimento coletivo, pareceme claro que Corsten está precisamente afirmando, embora não se dê conta disso, que o problema dessas não gerações é que elas não são capazes de ação comum e assim não conformam os "círculos culturais" amplos com os quais quer complementar a conceituação de Mannheim sobre a experiência. Em outras palavras, não são capazes de construir uma "identidade coletiva”. Isso significa que permanecem com baixo nível de centramento (questão que discutirei adiante), o que o leva a recusar-lhes a categorização como gerações. Mannheim, embora isso estivesse já de certa forma implícito em seu tratamento, fora mais cuidadoso, jamais afirmando tal coisa. Todavia, experiências comuns, "intenções básicas", "conteúdos comuns" são sempre conceitos que surgem em seu texto como que apontando para níveis superiores de construção das gerações como coletividades - a exemplo do que se passara com Marx no que toca às classes sociais. Isso se patenteia em sua afirmação de que para a continuidade e renovação da vida social o esquecer é tão importante como o lembrar. A morte das gerações possibilita o esquecimento, mas a seleção histórica do pensamento se faz de forma "reflexiva" ou não (cf. Mannheim, 1928, pp. 532-3).

Seria precisamente essa reflexividade, isto é, autoconsciência possível apenas sobre a base de uma "unidade de geração", que se afirma na obra de Mannheim, com diferenças em diversos estágios (naquela altura nos quadros de uma "sociologia do conhecimento"), como aquilo que possibilitaria uma reconstrução racional da sociedade (cf. Kettler, Meja e Stehr, 1990, que inclusive se utilizam do conceito de geração para interpretar a trajetória intelectual do próprio Mannheim). Ou seja, a geração "para si”, com alto nível de identidade - e possivelmente de organização - isto é, com alto nível de centramento, acaba por ser postulada ao menos implicitamente como tema crucial para uma mudança social racional. Assim, como se vê, uma geração, para ser desta forma classificada, deve ser pensada como assumindo forma plena somente quando se encontra ciente de si mesma. É verdade que se pode descobrir sugestões - como a da passagem que aponta para a possibilidade de efeitos geracionais “inconscientes", em sentido lato, ou seja, implicando meramente desconhecimento da parte do sujeito (cf. Schuman e Scott, 1989, p. 360) - porém isso não apenas se constitui em exceção na literatura sobre o tema como quando ocorre não produz maiores conseqüências.

Um problema adicional quanto à teoria de Mannheim foi aventado por Kertzer (1982; cf. também Foner, 1984, p. 205), que acusa o que seria a imprecisão do uso do termo "geração", preferindo falar de "coortes" para designar grupos etários e reservando o conceito de gerações para referir-se à sucessão de indivíduos dentro das linhagens, típicas de sociedades nas quais as relações de parentesco cumprem papel sobremaneira importante na vida social. Até certo ponto isso é verdade, mas creio que problemas sérios tam- 
bém se apresentam nesse tipo de redução proposta por Kertzer. De qualquer modo é interessante assinalar que a idéia de coortes aponta para uma noção de estratificação etária associada com papéis e status e que as pessoas nascidas no mesmo período os assumem no tempo sucessivamente (cf. Kertzer e Keith, 1984, pp. 29ss). ${ }^{3}$ Uma outra contribuição na sociologia, que entretanto permaneceu marginal ao núcleo da disciplina, é oferecida pelo modelo de desenvolvimento individual proposto mormente por Riley (1986; veja ainda Kohli e Meyer, 1986). Em particular ela chama a atenção para o fato de que há vários critérios sociais para tratar-se da idade e que não apenas a infância e a juventude, mas toda a ontogênese é contínua e implica processos de desenvolvimento do indivíduo, sendo essa progressão em grande parte uma construção social.

Por seu turno a antropologia, como mencionei acima, engajou-se no tema das idades e das gerações de forma decisiva. ${ }^{4}$ Talvez o modelo mais amplo nessa disciplina se deva a Fortes (1984). Constatando que embora apenas no ocidente e em algumas outras sociedades, como a romana ou aquelas que se filiam ao islã, a idade cronológica - isto é, marcada por datas fixas e universais - seja fundamental e mesmo conhecida, o envelhecimento e a passagem de uma idade a outra é um problema que se põe para todas as sociedades. Em particular ele destaca a centralidade disto para a obtenção de direitos e deveres político-jurídicos na sociedade mais ampla. Ele escolhe então lidar com a noção antropologicamente difundida de "estágios de maturação", que possuem uma base biológica porém são culturalmente definidos, e que implicam a assunção de posições sociais distintas, de acordo com as capacidades que os indivíduos manifestam ao longo do "ciclo de vida individual" (cf. Fortes, 1984, pp. 99-101; cf. também Beall, 1984, pp. 83-4), para o que se utiliza de idéias de Riley. Estágios de maturação são característicos de todos os primatas e são em geral definidos como imaturidade (infantil e juvenil), adolescência e fase adulta (jovem, de meia-idade e velhice), que variam para cada tipo de primata. A flexibilidade desses estágios na espécie humana é contudo muito superior a de qualquer outro primata (cf. Dolhinow, 1984, especialmente p. 66). Assim é mister distinguir ainda "classes etárias" (age grades) de "grupos etários" (age sets); aquelas se devem à maturação, estes à definição por grupos de idade cronológica (cf. Maybury-Lewis, 1984, pp. 128-9). Os argumentos de Maybury-Lewis acerca da existência de grupos etários, além de estágios maturacionais, entre os índios do Brasil Central põem em dúvida fortemente a idéia de irrelevância da idade cronológica para a maior parte das sociedades humanas tal como postulado por Fortes e Riley.

O que significaria "geração" no quadro conceitual de Fortes e a que se contrapõe? Para ele, calcadas genealogicamente, as gerações se geram unicamente no núcleo familiar de pais e filhos e sua sucessão constitui condição "sine qua non do processo reprodutivo", tanto no que tange à substituição física dos membros da sociedade quanto no que toca a sua substituição social e cultural. Essa estrutura geracional pode e costuma de fato ser estendida para
Ryder (1965) alternativamente apontou que experiências comuns, em que eventos importantes funcionam como marcos, podem ser pensadas como conformando coortes. Não necessariamente os indivíduos têm consciência disso, a começar pelos coortes conformados por datas de nascimento, segundo ele apenas um dos critérios para defini-los. Com essa tese há contudo um deslizamento explícito na direção da definição mannheimiana de geração e, de acordo com o modelo de variáveis que proporei abaixo, uma confusão de seus diversos elementos, embora Ryder esteja correto ao enfatizar que coortes evoluem no tempo.

4 Mas é mister assinalar que sua terminologia não é de modo algum sempre sistemática e uniforme. 
o conjunto das relações sociais quando há um sistema classificatório de parentesco. A idade, seja tratada cronologicamente ou meramente em termos da "ordem de nascimento", é fundamental para as estruturas familiares e geracionais (cf. Fortes, 1984, pp. 102-5). Mas isso difere essencialmente da ordenação social por estágios de maturação e pode estar em tensão com ela, o que leva a manobras para harmonizar esses diferentes princípios, em particular quando imaturidade ou senilidade se mostram como empecilhos para o desempenho das funções que as posições geracionais demandam. Ordem de nascimento e genealogias geracionais também podem estar em tensão - por exemplo fazendo de um homem adulto um subordinado hierárquico de uma criança que é seu pai devido à poliginia e à estrutura familiar, malgrado ele pertencer a um "grupo etário" mais avançado no que tange à vida social em seu conjunto (por exemplo em relações interlinhagens ou políticas). A mutabilidade e a abertura normativa de sociedades ditas "arcaicas" se evidencia aliás mediante os "jeitinhos" e inovações produzidos para dar conta desses conflitos. Se a perspectiva de Fortes ajuda-nos a compor um quadro mais amplo e detalhado do que seriam as relações sociais de idade e a precisar o conceito de geração, um problema deve ser todavia afastado criticamente: não há dúvida de que a família é central para a definição das gerações. Mas, como veremos abaixo, não há porque reduzir a compreensão das gerações e a sucessão biológica e sociocultural aos processos que se relacionam direta e única e exclusivamente com a célula familiar, não obstante a possibilidade de estender seus princípios para o conjunto da sociedade por intermédio das relações de parentesco. Outros elementos devem ser aduzidos a essa intuição chave de modo a alcançarmos um conceito abrangente e adequado de geração.

\section{Gerações e subjetividade coletiva}

Buscarei agora propor uma conceituação ampla do tema das gerações, com recurso ao que alhures elaborei com a teoria da subjetividade coletiva. O próprio conceito de gerações se fará mais preciso, creio, por um lado, ao passo que, por outro, a teoria da subjetividade coletiva evidenciará sua efetividade e utilidade na pesquisa mais empiricamente orientada. Três passos serão a seguir dados: 1) definir o conceito de gerações mediante uma sintese das perspectivas que de forma lata fazem uso desta noção (sobretudo calcadas em Mannheim) e das que baseiam-se na idéia de coortes, sem abrir mão outrossim de seus apoios biológicos; 2) discutir como, no caso específico das gerações, se apresentam as diversas dimensões analíticas dos sistemas sociais; 3 ) propor uma noção de subjetividade coletiva que, escapando da noção cartesiana-hobbesiana de sujeito típica da tradição ocidental, seja capaz de conceituar as gerações de acordo com seus diversos níveis de centramento.

1) A crítica de Kertzer à imprecisão da noção mannheimiana de 
geração e à alternativa contida na noção de coortes não é desprovida de sentido. Mas ela é por demais abstrata e joga fora com a água do banho a própria criança. Coortes fazem sentido na realidade tão-somente por meio de sua inserção nas relações sociais de família e parentesco (já para não falar de sua inserção no conjunto das relações sociais); as idades cronológicas, dependendo do tipo específico de formação social, podem ter também estreita relação concreta com os diversos coortes, que não são contudo sempre e necessariamente definidos por elas - até porque nem sempre esse recurso de datação se acha disponível socialmente e assim é a própria maturação que serve decisivamente como critério para a definição dos coortes. Por seu turno, a própria maturação - existam critérios para estabelecer a idade cronológica ou não pode aparecer como uma variável independente ao lado das outras acima mencionadas. Isso não deve ser confundido, no entanto, com os processos especificamente biológicos de envelhecimento (que incluem o próprio nascimento), embora mais uma vez concretamente seja difícil distinguir a base biológica pura e simples dos processos de maturação, que contém um elemento sociocultural na espécie humana em grau muito superior ao que podemos identificar mesmo nos primatas superiores. Por outro lado, as relações familiares e de parentesco, elementos decisivos para pensarmos a conformação e a sucessão de gerações, só se tecem concretamente a partir das vivências individuais e coletivas dos agentes e dos processos reflexivos associados a essas vivências, às experiências que constituem a própria vida social.

Com isso, creio que três conjuntos de variáveis analíticas podem ser definidos para a elaboração de uma conceituação ampla e sintética das gerações. Em primeiro lugar a família e as relações de parentesco, que podem ser derivadas mais ou menos diretamente das relações que se traçam no núcleo familiar básico. Aqui temos ademais um contínuo que abarca desde padrões que tendem a se reduzir à família nuclear, com poucas e menos importantes ramificações para cima e para baixo (avôs e netos) ou lateralmente (tios, sobrinhos, primos, etc.), até sociedades em que relações de linhagem fornecem o eixo em que se assenta a totalidade da vida social. Em segundo lugar encontramos os coortes - grupos de pessoas nascidas em momentos próximos e que atravessam estágios sucessivos ao mesmo tempo. Para sua definição três elementos são relevantes: a idade biológica, a idade cronológica (quando essa datação se faz presente) e os estágios de maturação. Enfim, em terceiro lugar devemos pôr a experiência vivida e reflexivamente mediada dos indivíduos e coletividades, para a qual as diversas dimensões dos sistemas sociais, a serem abaixo discutidas, contribuem decisivamente. Destarte podemos resumir em um quadro sintético as diversas variáveis que comparecem ao conceito amplo de geração:

Agregue-se a isso que uma geração não se define isoladamente: é na interação com outras gerações que cada uma delas delineia sua identidade e contribui para a produção das outras. É nesses processos interativos que as 
gerações se moldam e são moldadas. Mais substantivamente, uma outra questão deve ser destacada: é preciso pensar a relação entre família e linhagem, de um lado, e coortes, de outro, de forma realmente independente, analiticamente decerto, porém muitas vezes inclusive em termos concretos, pois as próprias gerações, sendo definidas pelo cruzamento dessas duas variáveis, podem se opor àquelas primeiras: em várias sociedades elas se apresentam como um princípio harmônico de solidariedade que contrabalança ou se sobrepõe às rivalidades entre linhagens, como ocorre nas comunidades indígenas do Brasil Central, ou que garante a dominância dos mais velhos sobre os jovens, sendo este por exemplo o caso das comunidades originais da África Oriental (cf. Fortes, 1984, pp. 116; Maybury-Lewis, 1984, pp. 132-6). Enfim perceber

Dimensões hermenêutica, material, espaço-temporal, de poder

\section{Experiência vivida Reflexividade}

\section{GERAÇÃO}
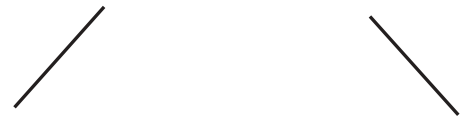

\section{Família, \\ Parentesco \\ nuclearidade linhagem}

\author{
Coorte \\ idade biológica \\ idade cronológica \\ estágios de \\ maturação
}

as gerações a partir desse conjunto de critérios relaciona-se aos pontos de vistas em si mesmos múltiplos que os próprios agentes sociais sustentam em sua vida cotidiana, conquanto seja possível a construção de modelos (o que com frequiência autores que privilegiam a definição de coortes fazem) que não correspondem diretamente à própria concepção "leiga" das estruturas e relações geracionais. As gerações são fenômenos socialmente multifacetados e amiúde incongruentes entre si em termos de sua construção social na "dimensão hermenêutica" dos sistemas sociais, a qual examinaremos mais detidamente a seguir. 
2) O ponto de vista de que as gerações teriam na biologia seu suporte fundamental soa hoje um tanto ou quanto estranho e cru, uma vez que a construção social das identidades é fenômeno amplamente estabelecido nas ciências sociais. No caso em tela não poderia ser diferente - não cabe de modo algum a redução das gerações aos processos de reprodução e transmissão genética, nem meramente aos ciclos do corpo. Quer isto dizer que não têm nada a ver com isso? Aí estaríamos forçando o argumento. As gerações encontram de fato no corpo e na sucessão biológica um substrato fundamental, conquanto não absoluto nem exclusivo, inclusive naquelas sociedades que já fazem seus membros passarem por processos contínuos de socialização extremamente contingentes e abertos, "reflexivos" (em sentido lato) (cf. Turner, 1998). Nesse sentido, como observado acima, compartilhamos com os primatas os diversos estágios maturacionais que levam os indivíduos biológicos do nascimento à morte, conquanto na espécie humana as etapas do ciclo vital patenteiem uma grande abertura e contingência decerto superior. Em sociedades cuja ligação com a natureza é mais direta e imediata, obviamente os ciclos biológicos reprodutivos e de envelhecimento têm mais peso, pois a cultura os reelabora sem contudo despregar-se deles inteiramente. Nas sociedades modernas, contemporaneamente em particular, isso é modulado em mediações ainda mais complexas, com as fronteiras geracionais se mostrando manifestamente mais fluidas e em princípio mais indeterminadas.

Além disso, se a constituição corporal das diversas coletividades que se sucedem historicamente é fundamental para a definição do que constitui uma geração, ou seja, se sua constituição material é decisiva para a definição de sua posição no continuum geracional, os recursos que pode mobilizar exteriormente são igualmente cruciais. Recursos materiais dependem para seu acesso de como se disponibilizam institucionalmente, isto é, de como regras e padrões de relacionamento social amplas e estáveis regulam as possibilidades diferenciadas de apropriação dos produtos do intercâmbio humano com a natureza. As gerações se definem em grande medida por isso. Isto é, seja sob uma forma coletiva, seja sob uma forma individual, as gerações podem atingir a propriedade, circunstancial ou permanente, de determinados recursos oriundos de nosso intercâmbio com a natureza. Obviamente, isso não pode ser descolado de como outras determinações sociais são estabelecidas, especialmente, é claro, em termos de organização das classes sociais, bem como de gênero. A apropriação diferencial dos recursos materiais disponíveis socialmente é, de qualquer modo, fundamental para a definição das gerações e das relações entre elas. Isso é verdade no que tange à produção bem como à distribuição e ao consumo do que resulta de nosso intercâmbio com a natureza (cf. Cohen, 1984), de forma direta ou indireta, por exemplo por intermédio dos vastos e inclusivos - e hoje controversos - sistemas de aposentadoria e previdência social típicos das sociedades ocidentais modernas. Concepções de justiça e equilíbrios variáveis se insinuam nessas coordenadas (cf. Rosanvallon, 1995). 
Podemos dizer com isso, portanto, que identificamos uma dimensão analítica básica da constituição das gerações enquanto subjetividades coletivas. Isto é, a sua constituição material e a sua capacidade específica de apropriação de recursos materiais. Mas, como já sugerido, o universo simbólico dentro do qual e a partir do qual as gerações se constituem é igualmente decisivo para que pensemos a sua constituição. Mais uma dimensão analítica das gerações enquanto subjetividades coletivas deve ser aqui identificada, $\mathrm{o}$ que pode ser definido como sua dimensão hermenêutica.

Aidade biológica costuma ser, como acima argumentado, um elemento básico para a caracterização das gerações. Quanto mais rígido o universo simbólico da civilização ou "sociedade" em tela, mais sói isso ocorrer. Mesmo aí, entretanto, pode-se supor variações que derivam da história contigente dessas coletividades, em particular em virtude dos efeitos de guerras e doenças, o que pode inclusive acarretar mudanças nos padrões etários de constituição das gerações. Quanto mais fluida a ordem social, quanto mais abertas as identidades, tanto menos impositivo esse padrão se mostrará, sem que deixe de ser relevante. É o que se observa na modernidade avançada, questão a que voltarei adiante.

Fato é que os padrões etários são sempre mediados pela dimensão hermenêutica dos sistemas sociais. Isso é verdadeiro no que tange à definição geral do universo simbólico - cognitivo, normativo e expressivo da coletividade mais inclusiva - assim como no que se refere à mediação entre as diversas perspectivas que constituem as diversas gerações. Isso implica o que Gadamer (1960, pp. 307-12) chamou de "fusão de horizontes" interpretativos de indivíduos e de coletividades que se põem em contato com sistemas simbólicos distintos dos seus - o que é parcial, porém inelutável, no caso de diferentes gerações, em virtude de suas distintas experiências históricas, como aliás assinalado pelo próprio Mannheim. Isso quer dizer que passados e presentes distintos convivem, com o que a tese da "não simultaneidade do simultâneo" pode ser reposta em termos da perspectiva de que gerações distintas não somente coexistem a partir de estágios biológicos distintos mas também a partir de experiências e identidades diferenciadas, sendo que a vida social consiste em parte em uma constante mediação de sentido, de uma permanente interpretação de significados entre coletividades que têm como referências passados e presentes distintos, assim como projeções de futuro díspares - com o que aquilo que podem saber e esperar, bem como o que devem fazer, distingue-se e pode mesmo tender à incompreensão, se bem que em muitas formações sociais uma maior continuidade do horizonte hermenêutico das gerações se manifeste.

Rituais podem ajudar a marcar a idade cronológica, mesmo que a maturidade sobretudo biológica do indivíduo não tenha sido alcançada ou tenha sido ultrapassada, e a maturação geracional pode ser também por eles pontuada. Esses são aliás momentos de incerteza e grande ansiedade e os rituais ajudam a lidar com essas transições (cf. Myerhoff, 1984). Assim tanto na 
demarcação de fronteiras entre elas quanto nas metamorfoses por que passam, rituais são amiúde fundamentais para a constituição hermenêutica das gerações.

Analiticamente um passo a mais deve ser dado a essa altura, conquanto empiricamente essa distinção esteja longe de se manifestar necessariamente de forma clara. Poder-se-ia assim afirmar que a constituição hermenêutica das coletividades, no caso em pauta das gerações, implica aquilo que as conforma internamente. Elas podem, todavia, recorrer a elementos externos, mobilizáveis expressiva ou instrumentalmente em suas relações com outras coletividades; vimos isso no caso da dimensão material das coletividades; o mesmo deve ser levado em conta ao pensarmos sua dimensão hermenêutica. Empréstimos e recursos a perspectivas oriundas de diversas dimensões da vida social (normativa, expressiva ou instrumentalmente) têm lugar no curso da interação entre as diversas gerações.

Não se deve, contudo, restringir o processo interativo de formação das diversas gerações exclusivamente a esse tipo de subjetividade coletiva. Na verdade são múltiplas as coletividades com que as gerações interagem, com as quais se cruzam. Acima mencionei de passagem as classes sociais; os "gêneros" e "raças" são outras referências que saltam imediatamente aos olhos. Essas são grandes coletividades que nesse sentido, ao perpassarem a vida social de forma ampla e muito abrangente, compartilham similaridades com as gerações (aliás também no que se refere amiúde a seu nível relativo de centramento, ao que voltarei abaixo). Muitas outras coletividades, ou seja, sistemas sociais, devem ser levados em conta ao se tratar do problema. Alguns são de pequeno porte, embora atravessem o conjunto da vida social: a família por antonomásia representa esse tipo de coletividade, evidenciando-se ainda como um ponto de referência fundamental para a própria produção das gerações. Em escala um pouco mais ampla encontramos a escola e os sistemas de ensino em geral, calcados claramente em princípios etários cronológicos na modernidade. Outro caso é o do estado, a começar pela produção da legislação que normatiza muitos aspectos da vida das diversas gerações, mas também em sua intervenção, por meio de suas diversas instâncias (médicas, judiciais, policiais, etc.), mais ou menos direta na vida social. Cronologias etárias são aí igualmente decisivas para a própria definição de cidadania-em seus diversos estágios, em termos de direitos e deveres - e esta por sua vez para a definição das gerações na modernidade (cf. Fortes, 1984, pp. 101 e 109-15). Hoje em dia o tráfico de drogas poderia ser apontado como um outro tipo de sistema social crucial em seu impacto mediante a interação com as gerações como subjetividades coletivas, no Rio de Janeiro bem como globalmente, ao recrutar adolescentes e estabelecer carreiras criminais com estágios definidos e em parte marcados pela idade (cf. Zaluar, 1994, cap. 12; Castells, 1998, p. 205). Outros sistemas sociais se cruzam de forma mais restrita com os das gerações: desde aqueles que conformam estilos de vida particulares, ou religiões específicas, e daí por diante. É nesse entrelaçamento interativo entre 
subjetividades coletivas diversas que se conformam tanto a vida social como as próprias gerações em si, que contribuem outrossim decisivamente para a forma e o conteúdo daquela.

Essas interações contam sempre com aqueles aspectos que recortei acima como duas dimensões decisivas das subjetividades coletivas em termos analíticos, a material e a hermenêutica. Mas a capacidade de uma coletividade influir sobre a outra não deve ser esquecida tampouco, podendo os sistemas sociais se organizarem de forma por assim dizer mais horizontal ou mais hierarquizada. Deparamo-nos, por conseguinte, com o poder como mais uma das dimensões analíticas dos sistemas sociais.

O "poder" pode ser conceitualmente definido de várias formas, com destaque para uma visão de linhagem hobbesiana, que lhe atribui um caráter de soma zero e o caracteriza como a possibilidade de fazer com que um ator se comporte de forma adequada aos anseios de um outro, mais poderoso, mesmo que em princípio não o deseje; e uma outra, que aponta para a capacidade da coletividade de mobilizar-se conjuntamente para a ação, com o que uma soma positiva se estabelece internamente. Sem dúvida é possível pensar as gerações dentro das coordenadas desta segunda concepção. De qualquer forma, se podemos visualizar gerações como coletividades com poder variável em função de seus processos internos, é necessário percebê-las como capazes de dirigir ou mesmo impor umas às outras, e a outras subjetividades coletivas, cursos de movimento que se conformem com o que almejam, seja isso produzido de maneira intencional e organizada, ou se passe como fruto de ações individuais ou movimentos de subcoletividades que acabam por tomar uma feição que favorece esse poder de uma sobre outra ou sobre outros sistemas. Com frequiência no caso das gerações os "adultos" ou mesmo os "velhos", por razões institucionais e culturais, possuem mais poder dentro de um grande número de sociedades e em parte em função disso são capazes de mobilizar recursos externos, para além das vantagens proporcionadas por sua constituição material e hermenêutica. Definições em termos de maturidade, genealogia e cronologia cumprem papel crucial para a definição das relações de poder entre as gerações, não apenas naquelas em que isso é bastante explícito, nomeadamente no caso das "gerontocracias" ou nas hierarquias cronológicas que abundam nos sistemas educacionais das sociedades modernas, mas de forma mais difusa e geral, conquanto nem sempre sistemática.

Muito comumente a sucessão das gerações é vista como se processando no tempo. Creio que essa ainda é a concepção subjacente às idéias de Mannheim, malgrado a noção da "não simultaneidade do simultâneo" implicar já que cada "ponto do tempo" configure a polifonia da organização de espaços temporais. Tem-se aí uma abertura parcial para abandonar a concepção do tempo como uma variável fixa, "paramétrica", de cunho abstrato e externo aos objetos e relações sociais, proporcionando uniformidade e intervalos simétricos, os quais se expressa no tempo dos relógios e no calendário lunar ocidental. Acredito que seria contudo mais adequado pensar a sucessão 
das gerações levando-se em conta o que se pode ver como seus três elementos diacrônicos (biologia, maturação e cronologia) como o próprio processo temporal em si e como interno e intrinsecamente constitutivo das relações sociais. Não há tempo abstrato - salvo como uma construção humana moderna, que se expressa cientificamente na física newtoniana -, mas sim o desdobramento biológico e cultural da sucessão das coletividades de gerações que tornam a espécie humana uma espécie, tout court e em evolução. Essa é aliás uma característica que compartilhamos com as outras espécies e presta testemunho de nosso pertencimento a ambos os universos, o da natureza e o da cultura (cf. Adam, 1990).

Isso se torna ainda mais relevante se temos em mente que essa sucessão geracional não ocorre no vazio do espaço. Ao contrário, é em espaços concretos, dos quais o tempo é uma variável, que os processos de envelhecimento se dão e a sucessão das gerações se processa (cf. Östör, 1984, p. 302). Mesmo em formações sociais abrangentes e extremamente complexas, com uma configuração espaço-temporal que pode abarcar o planeta como um todo, é desta forma que devemos pensar a dimensão espaço-temporal e o seu cruzamento com as outras dimensões analíticas acima discutidas.

3) É preciso enfrentar enfim um problema que enunciei no início mesmo deste artigo, o qual diz respeito à noção de que se pode ou deve falar de gerações como sujeitos coletivos com relativa homogeneidade e, principalmente, unidade de ação - isto é, centramento elevado. Mannheim é mais sutil, como já notei, embora tenda a essa compreensão, mas outros autores a abraçam de forma direta e clara, como também apontado acima.

Em lugar de pensar que coortes - a partir de seus fundamentos biológicos, cronológicos ou maturacionais - e em seu cruzamento contraditório com as determinações de família e linhagem, forçosamente ensejam uma ação coletiva concertada, devemos adotar uma posição mais ampla. De fato este pode ser o caso, como por exemplo entre os homens Xavantes, que se organizam em "moities" definidas por grupos baseados em estágios de maturação e cronologia, as quais se contrapõem tanto às mulheres quanto às próprias famílias e linhagens. Produzem-se uma solidariedade entre eles e uma ação comum, que conta com identidades claramente compartilhadas e organização interna (cf. Maybury-Lewis, 1984, pp. 131-2). É possível também que as idades cronológicas - 18 anos, por exemplo, para o serviço militar obrigatório no Brasil - ou estágios maturacionais no mundo moderno - sobretudo no que toca à juventude ou à "Terceira Idade" - gerem movimentos culturais e políticos com identidade clara e grau ao menos razoável de organização. Organização esta que, aliás, pode ser estabelecida a partir de mecanismos internos ou ser exógena, como o que ocorre com o próprio alistamento militar no exemplo acima, o sistema formal de ensino ou inclusive movimentos musicais "jovens" que têm na indústria do entretenimento um pólo capital e poderoso. 
Nem sempre, porém, é isso que acontece. A identidade de certas subjetividades coletivas maturacionais pode ser muito difusa. O simples fato de haver nascido em 1960, por exemplo, tende a gerar elementos que subjazem, de formas múltiplas, ao comportamento de inúmeros membros da sociedade, mas a consciência disso é em geral muito reduzida. Sua organização é ademais provavelmente inexistente. Todavia um movimento - internacional inclusive - como a rebeldia juvenil dos anos 1960, embora possuísse diversos centros irradiadores - políticos e culturais - se manifestou de um sem número de formas (movimentos estudantis, partidos revolucionários, comunidades hippies, grupos e correntes do rock e da música pop). Em suma, o movimento das subjetividades coletivas é bastante descentrado. Se chega a apontar em uma direção comum isso pode resultar de esforço comum e intencional; isso pode ter lugar, todavia, meramente como uma conseqüência não intencional da ação de indivíduos e do movimento de coletividades que em princípio não visavam tal resultado.

Assim constatamos que o nivel de centramento das subjetividades coletivas é variável. Ele varia de acordo com a identidade e a organização das coletividades. Essa perspectiva nos ajuda a dar conta das gerações como fenômenos extremamente amplos, que atravessam a vida social em seu conjunto, porém também em termos de suas subdivisões. As intuições de Mannheim sobre os "grupos concretos" são portanto preservadas, mas afasta-se a tendência a pensar-se as coletividades geracionais com o modelo de sujeito reificado, cartesiano-hobbesiano, da Ilustração, ou seja, como autoconscientes e com forte capacidade de ação a partir de seus interesses racionalmente definidos e perseguidos. Observe-se finalmente que o nível de centramento das gerações e subdivisões geracionais não engendra por si maior ou menor impacto causal sobre as outras coletividades e o sistema social inclusivo. É o que atesta, por exemplo, a sucessão de diversas gerações de mulheres durante os séculos XIX e XX, as quais transformaram significativamente a posição do gênero feminino, em suas várias expressões, e o puseram, aliás, como crucial para a própria auto-concepção das gerações, superando o caráter predominantemente masculino da construção social dessas coletividades até então. A permanência e a mudança social assim se processam e ao se processarem alteram as próprias definições e autodefinições das gerações, bem como suas relações entre si e com outras subjetividades coletivas. Gerações são centrais para a mudança social, sem consistirem em um princípio de organização que possa ser em si e por si tomado para explicá-la (cf. Riley, 1986).

\section{Gerações e modernidade}

Gerações, da forma complexa e multifacetada que busquei articular acima, têm cumprido papel central na vida social no curso da evolução da espécie humana como um todo. Importa agora considerar em particular 
que elementos é possível singularizar no que concerne a sua conformação na modernidade.

\section{O ponto de vista mais conhecido e sistemático acerca do tema} foi proposto por Eisenstadt, e foi profundamente marcado pelo funcionalismo e pelas "variáveis de parâmetro" que Parsons cristalizou dicotomicamente na sociologia norte-americana nos anos 1950. Eisenstadt queria entender em que condições a idade é decisiva para a "alocação de papéis" e para as "fronteiras" entre os grupos, e assim descobrir se a graduação etária leva a interações concretas. Chegou à conclusão que em "sociedades universalistas e de realização" (nomeadamente a sociedade norte-americana de meados do século XX), um indivíduo não pode atingir status pleno seguindo somente os padrões atributivos e particularistas da família. Isso enseja grupos etários homogêneos, que tornam mais fácil a transição da família para a sociedade mais ampla: os jovens podem manter a segurança emocional e expressar sua "personalidade total" - através de relações atributivas, que são contudo difusas, solidárias e orientadas coletivamente. Esses grupos funcionam como um grupo "primário", que é entretanto aberto. Isso se dá sem prejuízo de sua perspectiva universalista e também instrumental em grande medida. Os grupos homogêneos de idade desempenham, portanto, uma função integrativa, além de manifestarem uma "tendência inerente à solidariedade", graças à "definição comum de espaço de vida e destino" e ao "compartilhamento de tensões e experiências emocionais". Grupos etários fornecem "esferas de ligação" entre a família e os sistemas político, ocupacional e geral de valores da sociedade. Por isso eles se destacam e assumem tamanha visibilidade nas sociedades modernas, diferenciadas, ao contrário do que se passa em sociedades com fortes estruturas de descendência, nos quais submergem (cf. Eisenstadt, 1956, pp. 34-46, 54-5 e 272-3). Em outras palavras, eles proporcionam uma mediação entre diversas fases maturacionais e estágios cronológicos do desenvolvimento individual na modernidade. Mas para que isso ocorra é necessário que a família seja capaz de gerar expectativas "realistas" em seus novos membros, que permitam sua harmonia com a sociedade em geral, do contrário padrões “desviantes" sobrevêm (cf. Eisenstadt, 1956, pp. 273-5).

Há muitos elementos interessantes nas teses de Eisenstadt, porém sua forte inclinação modernista e funcionalista gera problemas e limitações, ${ }^{5}$ às quais proporei algumas alternativas conceituais. No que segue desenvolverei meus argumentos tratando do tema da institucionalização do ciclo de vida na modernidade e enfrentando ainda sua suposta desinsti-tucionalização no que alguns autores concebem como a "pós-modernidade". Relacionarei a questão das gerações na modernidade aos mecanismos de desencaixe e reencaixe típicos desse tipo de civilização. Com isso veremos que as gerações fornecem um tipo importantíssimo de reencaixe na modernidade em suas diversas etapas.

Os processos de desencaixe dos indivíduos e das coletividades de contextos mais concretos e específicos de existência e seu reencaixe median-
${ }^{5}$ Maybury-Lewis (1984, p. 136) implicitamente observa que não se deve assumir uma perspectiva funcionalista que automaticamente atribui funções integrativas, de ligação entre a família e a sociedade, às gerações e grupos etários homogêneos, conclusão que propõe após analisar os padrões divergentes de desenvolvimento desse tipo de organização geracional no Brasil Central e na África Oriental. A ideologia ou seja, a dimensão hermenêutica da vida social, em sua tessitura contingente - é fundamental para a conformação das gerações e de seu relacionamento com as outras subjetividades coletivas. 
te, em particular, o estatuto da cidadania e dos processos capitalistas, implicando uma brutal reordenação e o alargamento das relações espaço-temporais, gerou um tipo de indivíduo abstrato e a princípio sem qualidades atributivas (cf. Domingues, 1999a, conclusão; 1999b, cap. 1). Os processos de maturação tradicionais e inclusive de cronologização que porventura se apresentavam nas sociedades anteriores à modernidade foram nesse movimento deslocados, perdendo assim a sua centralidade, embora não tenham de maneira nenhuma desaparecido de todo. As gerações não ficaram imunes a esse impacto. Novas identidades se fizeram necessárias em termos mais concretos, pois aquelas abstratas se mostraram patentemente insuficientes para qualificar indivíduos e coletividades. Contingência e abertura crescentes se impõem a essas novas identidades concretas à medida que a modernidade se aprofunda e tende a pôr em questão as tradições que inicialmente teceu (inclusive em termos de gerações).

Um tipo particular e altamente abstrato de cronologização se firmou no alvorecer da modernidade, similarmente ao que ocorreu com outras áreas da vida e do imaginário modernos (a saber, a concepção do indivíduo, da cidadania, do tempo, etc.). É nisso que muitos autores insistiram, ao assinalar que uma forma peculiar de desenvolvimento do ciclo vital foi com isso traçada. Nessa institucionalização do curso da vida as "regras sociais" gerais - abstratas - se impõem sobre características individuais e relações sociais específicas (cf. Held, 1986; Hareven, 1986; Riley, 1986; Fortes, 1984). Escola, direitos políticos e sociais, fases profissionais, aposentadoria, etc., se organizam em torno a cronologias rígidas e destarte organizam a vida dos indivíduos. Um tipo de reencaixe foi proporcionado portanto por essa institucionalização do curso da vida por meios cronológicos. Identidades e relações sociais claras etariamente auxiliaram incontáveis coortes a situar-se existencial e socialmente, em seus cruzamentos com outros elementos identitários e relacionais. Mais recentemente, o contrário estaria em curso, pois uma desinstitucionalização desse ciclo vital teria sido ativada (Held, 1986; Hareven, 1995; Debert, 1999). Se bem que seja preciso relativizar essa postulação, é factível dizer que os reencaixes evidenciam ainda maior contingência e abertura nesse sentido e os estágios maturacionais se afastam em parte, mas de modo algum totalmente, das classificações cronológicas (sistemas educacionais, direitos e muitos outros fenômenos dependem fortemente de cronologias etárias).

É nesse quadro que a tese original de Eisenstadt pode fazer um certo sentido. Não se trata, friso mais uma vez, de supor que os grupos etários homogêneos cumprem o papel funcional de ligar a família e a sociedade (ou falham disfuncionalmente em cumpri-lo). Na verdade eles operam em situações de grande contingência na modernidade. Inicialmente as carreiras de trabalhador pouco educado mas logo incorporado ao mundo do trabalho, por um lado, ou indivíduo de classe média ou alta incorporado a sistemas formais ou informais de capacitação técnica ou de formação universitária, por outro, ou 
ainda o casamento e a maternidade para as mulheres, se não reduziam a importância da idade cronológica e mesmo das fases de maturação para a conformação das identidades individuais e coletivas, com certeza não favoreciam o aparecimento de estilos de vida e formas de sociabilidade baseados na homogeneidade de idades. Outras determinações sociais se mostravam mais poderosas na conformação de identidades e na produção de relações sociais e formas de sociabilidade. Aos poucos a vida social se fez mais aberta e as gerações vieram a oferecer pólos identitários e de sociabilidade mais relevantes, sobretudo em termos juvenis a princípio. Com isso esses tipos particulares de subjetividade coletiva, "grupos etários" homogêneos, puderam "funcionar" dando vazão quase ritualisticamente a ansiedades, organizando vivências e emoções comuns, porém também gerando ethos e "subculturas" específicas, as quais poderiam ou não ser congruentes com valores sociais gerais legítimos e/ou com os meios para alcançá-los.

Assim muitos grupos jovens, com frequiência universitários, realmente buscam nos valores mais gerais da modernidade inspiração para sua demanda de novas instituições, como Parsons e Platt (1973) propuseram de modo percuciente ao discutir o que chamaram de "revolução educacional", ou como autores de inspiração mannheimiana costumam fazer quanto a movimentos jovens de modo geral (cf. Gruppo, 2000). Mas o contrário pode ser verdadeiro, e contingentemente eles podem simplesmente adotar meios ilegítimos para atingir fins legítimos, para perfilhar os termos da conhecida equação de Merton (1968, cap. 6). Nem por isso dever-se-ia acusar a família de fomentar expectativas irrealistas - é antes à incapacidade da sociedade de propor alternativas de todo legítimas e integrativas que seria prudente e justo voltar as admoestações. Eventualmente valores e instituições talvez sejam postos em xeque. Ou quiçá nada disso esteja efetivamente em pauta, como é o caso com a miríade de grupos jovens que se renovam cotidianamente no mundo moderno, preocupados com facetas mais prosaicas do reencaixe individual e coletivo. Seja como for, não há necessidade de recorrer ao funcionalismo para explicar o porquê da existência desses processos e dessas subjetividades coletivas; devemos sim encará-los como construções sociais contigentes que emergem proporcionando reencaixes identitários e relacionais, e ao fazê-lo abraçam ou rejeitam valores e instituições sociais as mais variadas, facilitando ou complicando certos processos sociais e apresentando-se como uma variável da solidariedade social.

Dois fenômenos etários têm chamado em particular a atenção dos pesquisadores mais recentemente: a juventude (cf. Melucci, 1996b, cap. 6; Vianna, 1997), por bastante tempo fenômeno inclusive com foros de exclusividade; e a "Terceira Idade", que agora atrai os holofotes sobremaneira, em parte devido mesmo ao aumento significativo da expectativa de vida nas sociedades modernas (cf. Featherstone \& Wernick, 1995; Debert, 1999). Por outro lado à idade adulta madura, no mais das vezes reprodutiva e produtiva, tem sido dada pouca atenção, os universos característicos dessas fases tendo 
sido tratados por outras áreas, como a sociologia do trabalho, o feminismo, etc. A que se deve isso? Uma hipótese interessante é que são essas exatamente as faixas em que a entrada no mercado de trabalho ainda não se realizou ou então que o êxito dele já teve lugar. Em suma, as juventudes e "terceiras idades" oferecem reencaixes, relações sociais e identidades que contornam os vazios que os fenômenos típicos das biografias individuais na fase adulta madura normalmente preenchem. O cidadão trabalhador colocado no mercado de trabalho (se bem que hoje o desemprego decerto ofereça problemas crescentes e peculiares) e pai de família bem como a dona de casa casada e com filhos - ou seja, adultos jovens ou de meia-idade - não apresentavam problemas que merecessem ser estudados com foco particular. Uma pluralização crescente vem se afirmando na construção social dessas fases do ciclo vital caracterizadas como juventude e velhice, ao mesmo tempo em que tendem a se dilatar. Em que medida pode-se esperar algo semelhante para fase intermediária, a mais larga, da evolução individual? Conjura a radicalização da modernidade algo nessa direção? Até certo ponto a pluralização dos reencaixes e dos estilos de vida já responde a essa indagação afirmativamente. Se isso terá impacto afinal sobre a própria forma de pensarmos as gerações é contudo questão que permanece em aberto.

Recebido para publicação em fevereiro/2002

KEY WORDS:

modernity, subjectivity, generations.
DOMINGUES, José M. Generations, modernity and collective subjectivity. Tempo Social; Rev. Sociol. USP, S. Paulo, 14(1): 67-90, May 2002.

ABSTRACT: Generations as a sociological question, conceptually and empirically, have received some attention recently. However, they remain undertheorized, in general in terms of their particular configurations in modernity. This article reviews the sociological and anthropological literature about the topic and proposes to reconceptualize it, drawing upon the concept of "collective subjectivity". It then resumes its analyses in the bounds of modern society.

\section{REFERÊN CIAS BIBUOGRÁFICAS}

AdAm, Barbara. (1990) Time and social theory. Cambridge, Polity.

BEALl, Cynthia M. (1984) Theoretical dimensions of a focus on age in physical anthropology. In: KeRTZER, David I. \& KeITH, Jennie (orgs.). Age and anthropological theory. Londres e Ithaca, NY, Cornell University Press. 
Castells, Manuel. (1998) End of millennium. Oxford, Blackwell.

Cohen, Ronald. (1984) Age and culture as theory. In: Kertzer, David I. \& KeITH, Jennie (orgs.). Age and anthropological theory. Londres e Ithaca, NY, Cornell University Press.

Corsten, Michael. (1999) The time of generations. Time \& Society, 8.

DEBERT, Guita Grin. (1999) A reinvenção da velhice: socialização e processos de reprivatização do envelhecimento. São Paulo, Edusp.

Dolhinow, Phyllis. (1984) The primates: age, behavior, and evolution. In: Kertzer, David I. \& KeITH, Jennie (orgs.). Age and anthropological theory. Londres e Ithaca, NY, Cornell University Press.

Domingues, José Maurício. (1995) Sociological theory and collective subjectivity. Londres, Macmillan.

. (1996) Sistemas sociais e subjetividade coletiva. Dados, Rio de Janeiro, 36.

(1999a) Criatividade social, subjetividade coletiva e a modernidade brasileira contemporânea. Rio de Janeiro, Contracapa.

(1999b) Sociologia e modernidade. Para entender a sociedade contemporânea. Rio de Janeiro, Civilização Brasileira.

Eisenstadt, Schmuel. (1956) From generation to generation. New York, Free Press.

Featherstone, Mike \& Wernick, Andrew (orgs.). (1995) Images of aging. Cultural representations of later life. Londres, Routledge.

Foner, Nancy. (1984) Age and social change. In: KerTZER, David I. \& KEITH, Jennie (orgs.). Age and anthropological theory. Londres e Ithaca, NY, Cornell University Press.

ForTes, Meyer. (1984) Age, generation, and social structure. In: KerTzER, David I. \& KeITH, Jennie (orgs.). Age and anthropological theory. Londres e Ithaca, NY, Cornell University Press.

Gadamer, Hans-Georg. (1960) Wahrheit und methode. Tübingen, J.C. B. Mohr.

GruPPO, Luis Antonio. (2000) A juventude. São Paulo, Difel.

HALPERIN, Rhoda. (1984) Age in cultural economics: an evolutionary approach. In: Kertzer, David I. \& Keith, Jennie (orgs.). Age and anthropological theory. Londres e Ithaca, NY, Cornell University Press.

Hareven, Tamara. (1986) Historical changes in the social construction of the life course. Human Development, 29.

. (1995) Changing images of aging and the social construction of the life course. In: Featherstone, Mike \& Wernick, Andrew (orgs.). Images of aging. Cultural representations of later life. Londres, 


\section{Routledge.}

Held, Thomas. (1986) Institutionalization and deinstitutionalization of the life course. Human Development, 29.

Kettler, David; Meja, Volker \& Stehr, Nico. (1990) Rationalizing the irrational: Karl Mannheim and the besetting sin of German intellectuals. American Journal of Sociology, 95.

KeRTZER, David I. (1982) Generation and age in cross-cultural perspective. In: Riley, Matilda W.; Abeles, Ronald \& Teitelbaum, Michael (orgs.). Aging from birth to death: sociotemporal perspectives. Boulder, Westview Press.

\& KeITH, Jennie. (1984) Introduction. In: (orgs.). Age and anthropological theory. Londres e Ithaca, NY, Cornell University Press.

Kohli, Martin \& Meyer, John W. (1986) Social structure and social construction of life stages. Human Development, 29.

MABURY-Lewis, David. (1984) Age and kinship: a structural view. In: KerTZER, David I. \& KeITH, Jennie (orgs.). Age and anthropological theory. Londres e Ithaca, NY, Cornell University Press.

Mannheim, Karl. (1928) Das problem der generationen.In: Wissenssoziologie. Berlim, Neuwied, Herman Luchterhand.

Melucci, Alberto. (1996) Challenging codes. Cambridge, Cambridge University Press.

Merton, Robert K. (1968) Social theory and social structure. New York, Free Press.

Minayo, Maria Cecília de Souza et alii. (1999) Fala galera. Rio de Janeiro, Garamond.

MYERHOFF, Barbara. (1984) Ritual and signs of ripening: the intertwining of ritual, time, and growing old. In: KerTZER, David I. \& KeITH, Jennie (orgs.). Age and anthropological theory. Londres e Ithaca, NY, Cornell University Press.

Östor, Ákos. (1984) Chronology, category, and ritual In: KerTzER, David I. \& KeITH, Jennie (orgs.). Age and anthropological theory. Londres e Ithaca, NY, Cornell University Press.

Parsons, Talcott \& Platt, Gerald M. (1973). The American university. Cambridge, MA, Harvard University Press.

RILEY, Matilda W. (1986) The dynamisms of life stage: roles, people, and age. Human Development, 29.

RYDER, Norman B. (1965) The cohort in the study of social change. American Sociological Review, 30.

Rosanvallon, Pierre. (1995) La nouvelle question sociale. Paris, Seuil. 
Schuman, Howard \& Scott, Jaqueline. (1989) Generations and collective Memory. American Sociological Review, 54.

Turner, Bryan. (1995) Aging and identity: some reflections on the somatization of the self. In: Featherstone, Mike \& Wernick, Andrew (orgs.). Images of aging. Cultural representations of later life. Londres, Routledge.

\& Eyerman, Ron. (1998) Outline of a theory of generations. European Journal of Social Theory, 1.

Vianna, Hermano (org.). (1997) Galeras cariocas. Territórios de conflitos e encontros culturais. Rio de Janeiro, Editora UFRJ.

Zaluar, Alba. (1994) O condomínio do diabo. Rio de Janeiro, Revan/Editora UFRJ. 